\title{
Power Generation Dispatch Considering Energy Value and Environmental Protection
}

\author{
Yantao Wang ${ }^{*}, 1,2$ and Xueshan $\operatorname{Han}^{1}$ \\ ${ }^{1}$ Key Laboratory of Power System Intelligent Dispatch and Control of Ministry of Education, Shandong University, \\ Jinan 250061, China \\ ${ }^{2}$ Key Laboratory of Power System Intelligent Dispatch and Control of Ministry of Education, Shandong University, \\ Jinan 250061, China
}

\begin{abstract}
Electric power industry should play a bigger role in energy conservation and emission reduction, while the ecosystem degradation rises because of the shortage of energy, the greenhouse effect and the environmental pollution. Power generation dispatch is the key practice in electric power industry. In this paper, the value based dispatch theory is proposed, which assigns the value to the natural resources according to the social development as well as environmental and economic reasons. The goal of this theory is to maximize the energy value through the market mechanism. The implementation is discussed based on a real case.
\end{abstract}

Keywords: Energy value, power system, power generation dispatch, value based dispatch.

\section{INTRODUCTION}

Human society's dependence on electricity improves continuously, because it has unique characteristics such as clean, flexible, and controllable. But the electric power industry is facing the increasing challenges in terms of energy and environmental issues. Electric power industry must solve the problem about how to understand and deal properly with the impact on energy and environment in the process of the electric power system development, so the growing demands for electricity can be satisfied, and the sustainable development of humanity can be guaranteed at the same time.

In the field of electric power system and its automation, the electric power system dispatch is a typical problem of optimal allocation of resources theory and engineering. It is one of the branches which lead to the development of mathematics, applied mathematics, numerical calculation, management and economics theory. In the whole process of the development of electric power system, every major change is related to the dispatch theory.

Since the 1920's, the dispatch theory has been extremely mature. The existing literature of the electric power system dispatch theory can be found from the monographs by Wood \& Wollenberg [1] and other professors [2-4]. Some classic dispatch methods embody the pursuit of energy value and efficiency, such as run-off-river hydropower plant generates the electricity first in the combined hydro-thermal power system, the hydropower plant with the adjustment capacity uses the water coal conversion equivalent to reflect the value of water, cogeneration power plant has generation

*Address correspondence to this author at the Key Laboratory of Power System Intelligent Dispatch and Control of Ministry of Education, Shandong University Jingshi Road, Jinan City 250061, China;

Tel: +86-531-88399003; E-mail: wangyantao@gmail.com priority, and so on. During this period, there are some attempts to consider emission problems [5, 6].

In the late 1980's, many countries introduced the competition to electric power industry to develop the electricity market. During the electric power industry's market-oriented reform process, the electric power system dispatch theory is gradually moving to the electricity marketbased economic dispatch problem. During that time, the significant progress is made in the electricity market structure, economic system, trading tools, optimization theory and practice [7-10]. Electricity commodity price signals, the responsibility (rights/interests) sharing of the participants and other issues are included into the dispatch theory to optimize the power system resource allocation through the market mechanism.

In recent years, the research on electric power system dispatch has focused on many issues, such as demand side response, environmental protection, risk, clean energy, wind power, microgrid and so on [11-16]. Energy-saving power generation dispatch method was proposed in 2007 [17], then some discussions on the implementation of the method were published [18-20].

In conclusion, after nearly a century of development, electric power system dispatch theory is more complete in terms of the model, algorithms and implementation. The unsolved problem is the environmental degradation and the shortage of exhaustible resources. To achieve it, the original dispatch concept which ignores the value of natural resources must be changed, and the value of resources and environment must be considered as the objectives of electric power system dispatch regulation.

The new dispatch idea should be established based on the accurate appraisal of the values of resources and environment to promote the energy-saving, and emission reduction based electric power system generation dispatch mechanism based on energy value needs to be established. 


\section{VALUE BASED DISPATCH THEORY}

\subsection{Meanings of the Value Based Dispatch}

The goal of the value based dispatch is to maximize the value of resources through the market regulation mechanism, under the constraints of the physics laws of power grid operation and resource limits [21]. Specifically, it is related to four aspects.

Firstly, the value based dispatch is a method to consider the value of natural resources directly. In the market environment, the purpose of electricity generation is to trade. The trading process includes not only the transfer of material, but also the transfer of value [22]. Because of the lack of the value of natural resources in the classical economics, which abides by the traditional dispatch method has not taken the value of natural resources into account, and then the natural resources value cannot participate in the economic system value circulation. Furthermore, resources cannot achieve the optimization allocation driven by price signal. The direct way to solve this problem is to break through the restriction of the classical economics, and put the value of natural resources into the value circulation of the economic system. Then the contradiction between the increasing energy demand and the sustainable development of society can be solved too.

Secondly, the value based dispatch follows the principle of resource allocation based on the market mechanism continuously. Market is an effective means of resources allocation. If the efficient market was set up, "the invisible hand" described in the economics would optimize the resource allocation when the market participants maximize their individual profits. But the precondition must be satisfied that the value of natural resources is considered. Therefore, the new dispatch decision-making method is neither the simple monopoly regulation, nor getting rid of the market mechanism. It is system integration.

Thirdly, the purpose of the value based dispatch is to maximize the value of resources. In the electric power system operation, there are too many choices about where, how, and what resources should be chosen to generate power. If one mode is decided, it means to give up the possible value obtained by others. It is the opportunity cost that we have to afford to make a decision. So, the best way of dispatch is to find the minimum opportunity cost under the given conditions. According to the duality theory, it is equal to finding the maxim value of resources. The purpose of value based dispatch is to turn minimizing the opportunity cost into maximizing the value of resources.

Finally, the value based dispatch is under restrictions of the physics laws of power grid and resource limitation. The value based dispatch is based on grid physical structure, it must follow the objective laws on grid, such as Kirchhoff's current law (KCL), Kirchhoff's voltage law (KVL) and generalized ohm law. The limitation of all kinds of resources, especially the constraints of the limitation of resources could be turned into electricity and the capacity of electricity generation emissions can be accommodated by environment, must be considered during the optimization of resource allocation by the value based dispatch.
In conclusion, a dispatch with these four properties would be the value based dispatch. It is not confined to the traditional economy idea that looking for the minimum consumption under monopolistic condition or seeking the maximum profit through the market mechanism. On the contrary, it attempts to find the operation mode minimum opportunity cost and the maximum value of natural resources.

\subsection{General Model of the Value Based Dispatch}

The general abstract model of the value based dispatch can be expressed as follows;

$$
\begin{aligned}
& \max \quad \alpha^{\mathrm{T}} x \\
& \text { s.t. } \quad \mathrm{g}(x) \leq 0 \\
& \mathrm{c}(x) \leq 0
\end{aligned}
$$

where $\alpha$ is the column vector of value factors; $x$ is the decision variable.

Formula (1) is the object function to achieve the maximum value of resources. Formula (2) is regular constraints in dispatch, includes power balance constraints, generator limit constraints, and grid security and reliability constraints. Formula (3) is added constraints for the value based dispatch, i.e. the characterization of the natural resources limit.

It could be concluded from formula $(1) \sim(3)$ that there are two problems that must be solved before establishing the model of the value based dispatch, the value factors and the added constraints. It is also the main difference between the value based dispatch and traditional dispatch.

In particular, the value based dispatch does not have certain specific model, but is a new dispatch concept with strong adaptability and vitality and can be combined with every situation.

\section{APPLICATION}

\subsection{A Model of the Value Based Dispatch}

\subsubsection{Objective Function}

The traditional economic dispatch model considers only the cost and emissions factors, but the energy factors. A new model of the value based dispatch considering energy consumption and environmental protection in electricity market is established.

$$
f=\left[f_{c}, f_{e}, f_{k}\right]
$$

where the parameters $f_{c}, f_{e}, f_{k}$ denote respectively the cost function, the $N O_{x}$ emissions function, and the energy consumption factor. Details are as follows.

\subsubsection{The Cost Function}

In the electricity market, the power generation enterprises may use different bidding strategies at different load levels and different times. The bidding curves could be various forms. Therefore, to the power grid, the curve shape of the cost for purchasing electricity should be in various types 
accordingly. The cost function in the new dispatch model is represented as follows:

$f_{c}=\sum_{t=1}^{T} \sum_{i=1}^{n} C_{i}\left(P_{i, t}\right) \cdot P_{i, t} I_{i, t}$

It is the objective function for the minimum cost based on all power generation enterprises' actual bid price. In the formula (5), $i$ is the number of the generator which bid in the electricity market. If there are $n$ generators in the market, then $i$ could be valued from 1 to $n$. And $t$ for the time; $T$ for the trading cycle; $P_{i, t}$ for the active power of generator $i$ in time $t$. $C_{i}\left(P_{i, t}\right)$ is the bid curve made by generator $i$ in time $t$, which is a function of the active power $P_{i, t}$ and the time $t$, and be different from one another according to the bid curve of different generator. $I_{i, t}$ represents the status of generator $i$ in time $t$, which equals to 1 if the generator $i$ is running in time $t$, or equals to 0 if the generator is off at that time.

\subsubsection{The $\mathrm{NO}_{\mathrm{x}}$ Emissions Function}

To minimize the polluting gas emissions, the emission function is represented as follows;

$$
f_{e}=\sum_{t=1}^{T} \sum_{i=1}^{n}\left[\alpha_{i}+\beta_{i} P_{i, t}+\gamma_{i} P_{i, t}^{2}\right] I_{i, t}
$$

Characteristics of the $N O_{x}$ emissions is expressed by quadratic curve, and $\alpha_{i}, \beta_{i}, \gamma_{i}$ are constant coefficients in quadratic curve of generator $i$.

\subsubsection{The Energy Consumption Factor}

In the traditional economic dispatch model, only two targets were considered, the purchase cost and the $N O_{x}$ emissions. The target of value based dispatch is coordination and optimization between the energy consumption, cost and emissions. So the energy consumption factor is proposed to take account of the important optimization goal, energy saving.

The expression of energy consumption factor is as follows;

$$
f_{k}=\sum_{i=1}^{T} \sum_{i=1}^{n} \theta_{i} P_{i, t}
$$

where $\theta_{i}$ is the energy consumption coefficient of generator $i$, which be made up of two parts, the category score and the energy consumption score of each generator;
$\theta_{i}=S_{c, i}+S_{g, i}$

where $S_{c, i}$ is the category score; $S_{g, i}$ is the generator energy consumption score.

The category score $\left(S_{c, i}\right)$ is graded according to the type and the utilization results of energy used by generator, as shown in Table 1.

In each category, the generators should be sorted by energy consumption level from low to high, or by emission level if they are at the same energy consumption level. The energy consumption score of each generator $\left(S_{g, i}\right)$ is its sort result minus 1 then divided by the amount of units in the category:

$$
S_{g, i}=\frac{\text { Sort result }-1}{\text { Amount of units in the category }}
$$

\subsubsection{B. Constraints}

\subsubsection{Power Balance Constraints}

$$
\sum_{i=1}^{n} P_{i, t} I_{i, t}=P_{D, t}+P_{L, t}
$$

where $P_{D, t}$ is the total load of the power system at time $t ; P_{L, t}$ is the loss of active power at time $t$.

\subsubsection{Generator Output Power Limit Constraints}

$I_{i, t} \cdot P_{i, \min } \leq P_{i, t} \leq I_{i, t} \cdot P_{i, \max }$

where $P_{i, \min }$ and $P_{i, \max }$ are respectively the minimum and maximum output of generator $i$.

\subsubsection{Spinning Reserve Constraints}

$$
\sum_{i=1}^{n} S_{i, t} I_{i, t} \geq S_{r, t}
$$

where $S_{i, t}$ represents the spinning reserve provided by the generator $i$ at time $t$, and $S_{r, t}$ represents the total amount of spinning reserve requirements.

\begin{tabular}{|c|c|}
\hline Category & $S_{c, i}$ \\
\hline Generators using wind, solar, ocean, water and other renewable energy without adjustment ability & 1 \\
\hline Generators using renewable energy with adjustment ability and garbage generators meeting the requirements of environmental protection & 2 \\
\hline Nuclear power generators & 3 \\
\hline $\begin{array}{l}\text { Cogeneration generators according to the principle of "heat will be electricity" and comprehensive resources utilization generators using waste } \\
\text { heat, waste gas, waste pressure, coal gangue, washed middling coal, coal bed methane, etc. }\end{array}$ & 4 \\
\hline Generators using natural gas and coal gasification & 5 \\
\hline Other coal-fired generators including cogeneration generators without the heat load & 6 \\
\hline Fuel generator & 7 \\
\hline
\end{tabular}

\subsubsection{Minimum On and Off Duration Constraints}

$$
\begin{aligned}
& \left(V_{i, t}^{o n}-T_{i}^{\mathrm{min}-o n}\right)\left(I_{i, t-1}-I_{i, t}\right) \geq 0 \\
& \left(V_{i, t}^{\text {off }}-T_{i}^{\mathrm{min}-o f f}\right)\left(I_{i, t}-I_{i, t-1}\right) \geq 0
\end{aligned}
$$

Table 1. Category score. 
where $V_{i, t}^{\text {on }}$ and $V_{i, t}^{\text {off }}$ are respectively the on and off duration of the generator $i$ at time $t ; T_{i}^{\text {min-on }}$ and $T_{i}^{\text {min-off }}$ are respectively the minimum on and off duration of generator $i$.

\subsubsection{Generator's Power Changing Speed Constraints}

$r_{d i} \Delta t \leq P_{i, t}-P_{i, t-1} \leq r_{u i} \Delta t$

where $r_{u i}$ and $r_{d i}$ are the maximum allowable power output rise and fall speed each minute of the generator $i ; \Delta t$ is the continuation of a period of time.

\subsubsection{Generator's Spinning Reserve Changing Speed} Constraints

$S_{i, t} I_{i, t} \leq S_{i \max } \Delta t$

where $S_{\text {imax }}$ is the maximum probability response of the spinning reserves of the generator $i$ inside unit time.

\subsection{Model Solution}

In the multi-objective decision making considering the energy consumption environmental protection and economic in general, there is no absolute optimal solution, and the decision-making result is closely associated with the subjective preferences of decision-makers. The interactive decision making method can fully reflect the subjective views of policy makers, which is a very reasonable way in the multi-objective decision making [23, 24].

Reference [25] proposed a double objective fuzzy optimization strategy. Firstly, the two single-objective deterministic models were solved for their respective objective function value. Secondly, stretching the target values to a certain extent and defining the objective function's membership function, thus the deterministic problem is fuzzified. Finally, using the maximum fuzzy satisfying method to transform the multi-objective problem into singleobjective nonlinear problems, and then solve them.

This method is applied to solve the proposed new model of value based dispatch considering energy consumption and environmental protection in electricity market.

\subsubsection{Fuzzify the Objective Functions}

The key step in the modeling process is to determine the membership function. The objective of model is to give full consideration to decrease energy consumption, lower purchase costs, and reduce environmental pollution, which meet all the constraints at the same time. So we should lower the cost, $N O_{x}$ emissions and energy consumption factor as far as possible. The lower semi-linear is selected for the membership function, so the membership function of the three optimization objectives should be respectively denoted as formulas (16), (17) and (18), and be shown in Fig. (1):

$$
\mu\left(f_{c}(x)\right)=\left\{\begin{array}{cc}
1 & f_{c}(x) \leq c_{01} \\
\frac{c_{01}+\delta_{01}-f_{c}(x)}{\delta_{01}} & c_{01}<f_{c}(x) \leq c_{01}+\delta_{01} \\
0 & f_{c}(x)>c_{01}+\delta_{01}
\end{array}\right.
$$

$$
\begin{gathered}
\mu\left(f_{e}(x)\right)=\left\{\begin{array}{cc}
1 & f_{e}(x) \leq c_{02} \\
\frac{c_{02}+\delta_{02}-f_{e}(x)}{\delta_{02}} & c_{02}<f_{e}(x) \leq c_{02}+\delta_{02} \\
0 & f_{e}(x)>c_{02}+\delta_{02}
\end{array}\right. \\
\mu\left(f_{k}(x)\right)=\left\{\begin{array}{cc}
1 & f_{k}(x) \leq c_{03} \\
\frac{c_{03}+\delta_{03}-f_{k}(x)}{\delta_{03}} & c_{03}<f_{k}(x) \leq c_{03}+\delta_{03} \\
0 & f_{k}(x)>c_{03}+\delta_{03}
\end{array}\right.
\end{gathered}
$$

In the formula (16) (18), $x=\left[P_{1, t} P_{2, t} \ldots P_{n, t}\right]^{T}$. In Fig. (1), $c+\delta$ represents the maximum acceptable purchasing cost, $N O_{x}$ emissions or energy consumption factor. The parameters $c_{01}, c_{02}$ and $c_{03}$ are the target values of the cost single-objective optimization model, the total $N O_{x}$ emissions single-objective optimization model and the energy consumption factor single-objective optimization model. On this basis, the domains of three objective functions are determined.

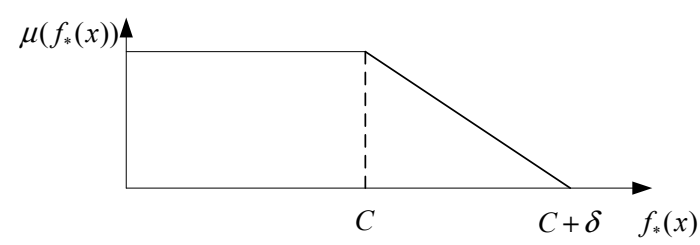

Fig. (1). Membership functions.

\subsubsection{Multi-Objective Fuzzy Optimization Model}

Being fuzzified, the solution of formula (4) is transformed into the problem of maximizing the degree of membership (i.e. satisfaction $\lambda$ ), which can meet the three objectives and all constraints, that is the problem, called $M$, of minimizing the $-\lambda$. It can be expressed as follows:

$\min -\lambda$

s.t. $f_{c}(x)+\delta_{01} \lambda \leq c_{01}+\delta_{01}$

$f_{e}(x)+\delta_{02} \lambda \leq c_{02}+\delta_{02}$

$f_{k}(x)+\delta_{03} \lambda \leq c_{03}+\delta_{03}$

$0 \leq \lambda \leq 1$

Formula $(10) \sim(15)$

\subsubsection{The Process of Solving}

Step 1: Enter the raw data to solve the single-objective deterministic model for the minimum cost. Calculate the purchasing $\operatorname{cost} c_{01}$ at each time period, the total $N O_{x}$ emissions $c_{02}$ [1], the energy consumption factor $c_{03}$ [1] the result of unit commitment, and the active power of every generator.

Step 2: Enter the raw data to solve the single-objective deterministic model for the minimum emissions. Calculate the $N O_{x}$ emissions $c_{02}$ at each time period, the total purchasing cost $c_{01}$ [2], the energy consumption factor $c_{03}$ [2], the result of unit commitment, and the active power of every generator. 
Step 3: Enter the raw data to solve the single-objective deterministic model for the minimum energy consumption factor. Calculate the energy consumption factor $c_{03}$ at each time period, the total purchasing cost $c_{01}$ [3], the $N O_{x}$ emissions $c_{02}$ [3], the result of unit commitment, and the active power of every generator.

Step 4: On the basis of step $1 \sim 3$, stretch the single targets, namely to determine $\delta_{01}, \delta_{02}, \delta_{03}$, thus fuzzify the deterministic problem.

The method to determine $\delta_{01}$ is to keep the value of $c_{01}+$ $\delta_{01}$ larger than $c_{01}$ but smaller than $c_{01}$ [2] and $c_{01}$ [3]. The methods for $\delta_{02}$ and $\delta_{03}$ are similar:

$$
\begin{aligned}
& \mathrm{c}_{01}<\mathrm{c}_{01}+\delta_{01}<\mathrm{c}_{01}[2], \mathrm{c}_{01}<\mathrm{c}_{01}+\delta_{01}<\mathrm{c}_{01}[3] \\
& \mathrm{c}_{02}<\mathrm{c}_{02}+\delta_{02}<\mathrm{c}_{02}[1], \mathrm{c}_{02}<\mathrm{c}_{02}+\delta_{02}<\mathrm{c}_{02} \text { [3] } \\
& \mathrm{c}_{03}<\mathrm{c}_{03}+\delta_{03}<\mathrm{c}_{03}[1], \mathrm{c}_{03}<\mathrm{c}_{03}+\delta_{03}<\mathrm{c}_{03}[2]
\end{aligned}
$$

If the requirements to the energy consumption factors, environmental factors or economic factors are different, the stretching target could be selected at different levels. Theoretically, the smaller the $\delta 01, \delta 02$ and $\delta 03$ are, the better those factors are, but the difficulty to solve them will increase accordingly.
Step 5: Put the parameters $c_{01}, \delta_{01}, c_{02}, \delta_{02}, c_{03}$ and $\delta_{03}$ into formulas $(20) \sim(22)$ respectively, the membership function expression can be drawn.

Step 6: Transform the multi-objective problem into the single objective nonlinear problem $M$ by maximizing satisfaction.

Step 7: Solve the problem $M$, and then get the greatest satisfaction at each time period, the unit commitment, and the power output of every generators.

\subsection{Simulation and Result Analysis}

There are six generators in the simulation system, and the calculation cycle is divided into 24 periods, some parameters are taken from reference [26]. To simplify the simulation, the active power losses have been credited to the load, and the bidding curve was selected as the function $c_{i}\left(P_{i, t}\right)=a_{i} P_{i, t}+b_{i}$. The bidding curves are the same at various periods. The parameters and the required load are shown in Tables $\mathbf{2}$ and $\mathbf{3}$

The target values of the tri-objective fuzzy optimization, the dual-objective optimizations, the single-objective

\begin{tabular}{|c|c|c|c|c|c|c|c|c|c|c|c|c|c|}
\hline \multirow[t]{2}{*}{ No. } & \multicolumn{2}{|c|}{$\begin{array}{l}\text { Constant Coefficient in the } \\
\text { Bidding Function (\$/MWh) }\end{array}$} & \multicolumn{3}{|c|}{$\begin{array}{c}N O_{x} \text { emissions } \\
\quad\left(10^{-6} \mathrm{t} / \mathrm{h}\right)\end{array}$} & \multicolumn{2}{|c|}{$\begin{array}{l}\text { Output Limit } \\
\text { (MW) }\end{array}$} & \multirow{2}{*}{$\begin{array}{l}T_{i}^{\min -o n} \\
\quad \text { (h) }\end{array}$} & \multirow{2}{*}{$\begin{array}{l}T_{i}^{\text {min-off }} \\
\quad \text { (h) }\end{array}$} & \multirow{2}{*}{$\begin{array}{c}r_{u i} \\
(\mathbf{M W} / \mathbf{m i n})\end{array}$} & \multirow{2}{*}{$\begin{array}{c}r_{d i} \\
(M W / \min )\end{array}$} & \multirow{2}{*}{$\begin{array}{c}S_{\text {imax }} \\
(\mathrm{MW} / \mathrm{min})\end{array}$} & \multirow{2}{*}{$\theta_{i}$} \\
\hline & $a_{i}$ & $b_{i}$ & $\gamma_{i}$ & $\boldsymbol{\beta}_{i}$ & $\alpha_{i}$ & $\boldsymbol{P}_{i, \min }$ & $\boldsymbol{P}_{i, \max }$ & & & & & & \\
\hline 1 & 2.12 & 1801.5 & 3.149 & -6.554 & 4.091 & 50 & 150 & 3 & 3 & 0.750 & 0.750 & 0.750 & 6.1 \\
\hline 2 & 2.61 & 1535.4 & 3.238 & -5.374 & 2.543 & 75 & 280 & 5 & 5 & 1.400 & 1.400 & 1.400 & 6.6 \\
\hline 3 & 2.89 & 1264.3 & 4.586 & -5.094 & 4.257 & 120 & 320 & 5 & 5 & 1.600 & 1.600 & 1.600 & 6.8 \\
\hline 4 & 1.48 & 1213.0 & 3.380 & -3.550 & 5.326 & 125 & 445 & 8 & 8 & 2.225 & 2.225 & 2.225 & 6.3 \\
\hline 5 & 1.27 & 1195.4 & 5.028 & -6.047 & 5.639 & 250 & 520 & 8 & 8 & 2.600 & 2.600 & 2.600 & 4.1 \\
\hline 6 & 1.35 & 1128.5 & 5.155 & -5.555 & 6.130 & 250 & 550 & 8 & 8 & 2.750 & 2.750 & 2.750 & 4.5 \\
\hline
\end{tabular}
optimizations and their comparison are listed in Table 4.

Table 2. Parameters of generators.

Table 3. Loads and reserves during operation.

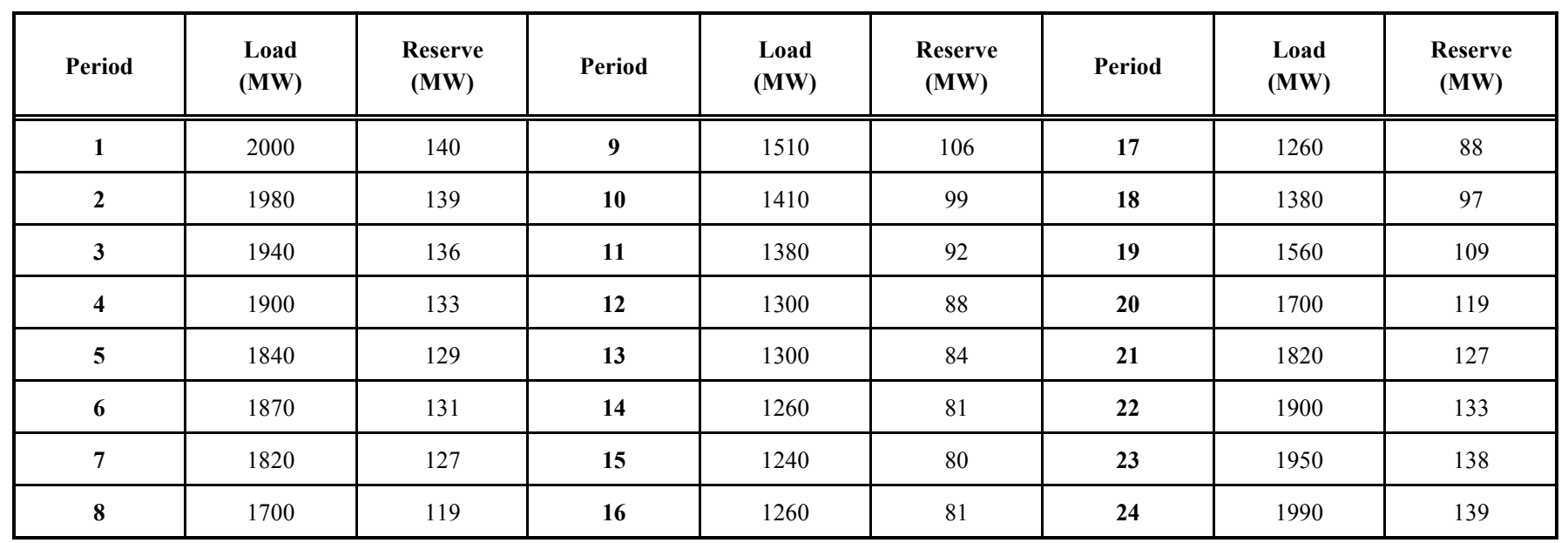


Table 4. Results comparison.

\begin{tabular}{|c|c|c|c|c|c|}
\hline Target & Cost only & Emissions only & $\begin{array}{c}\text { Energy Consumption } \\
\text { Factor Only }\end{array}$ & $\begin{array}{c}\text { Dual-Objective Fuzzy } \\
\text { Optimization }\end{array}$ & $\begin{array}{c}\text { Tri-Objective Fuzzy } \\
\text { Optimization }\end{array}$ \\
\hline \hline Cost (\$) & 70603 & 72850 & 74587 & 70944 & 72316 \\
\hline Emissions (t) & 70.6521 & 55.3368 & 86.7164 & 62.1539 & 63.9076 \\
\hline Energy consumption factor & 198376 & 229581 & 186513 & 217724 & 192645 \\
\hline
\end{tabular}

Figs. (2-7) show the load distribution of every generator in the various optimizations.

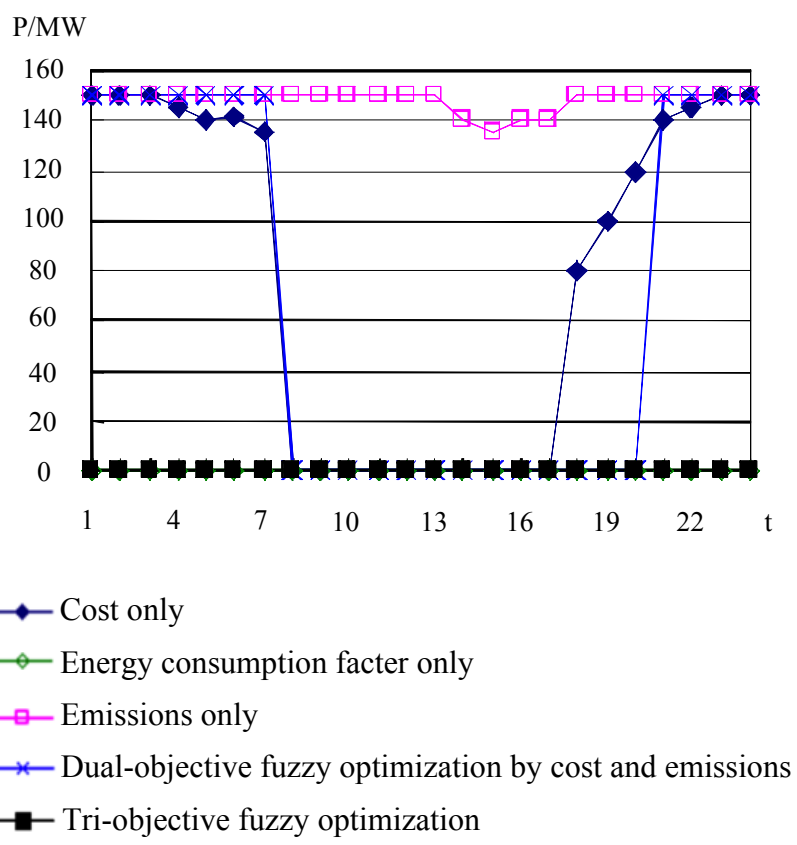

Fig. (2). Generator 1 output power curves.

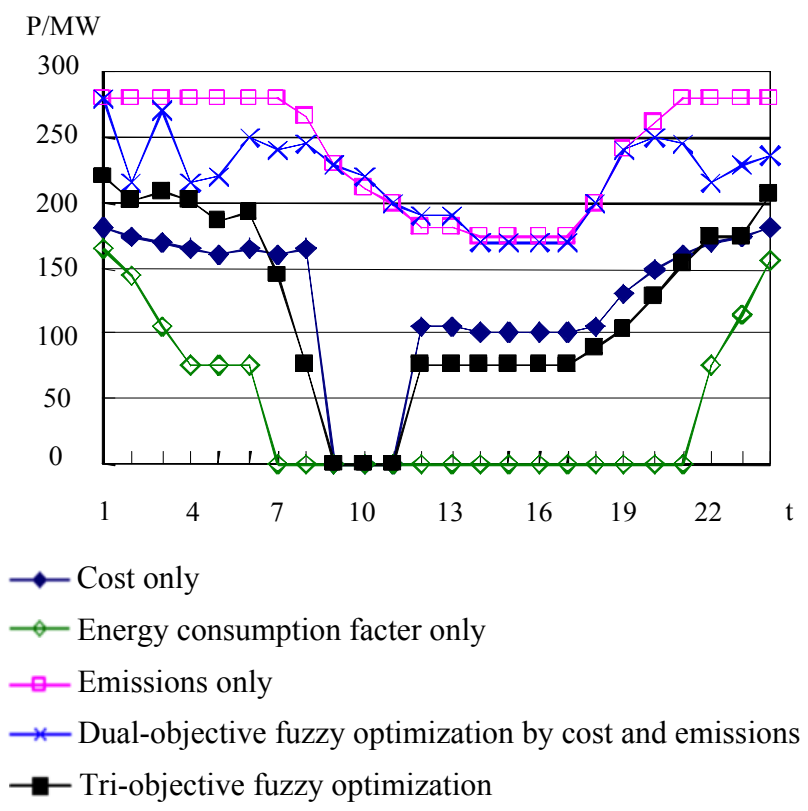

Fig. (3). Generator 2 output power curves.

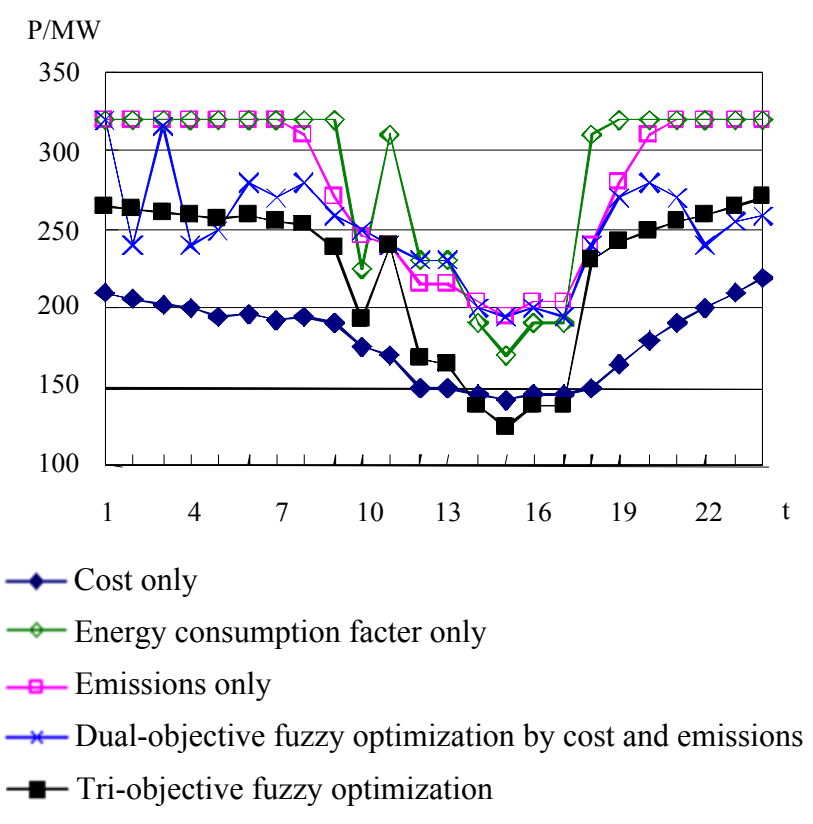

Fig. (4). Generator 3 output power curves.

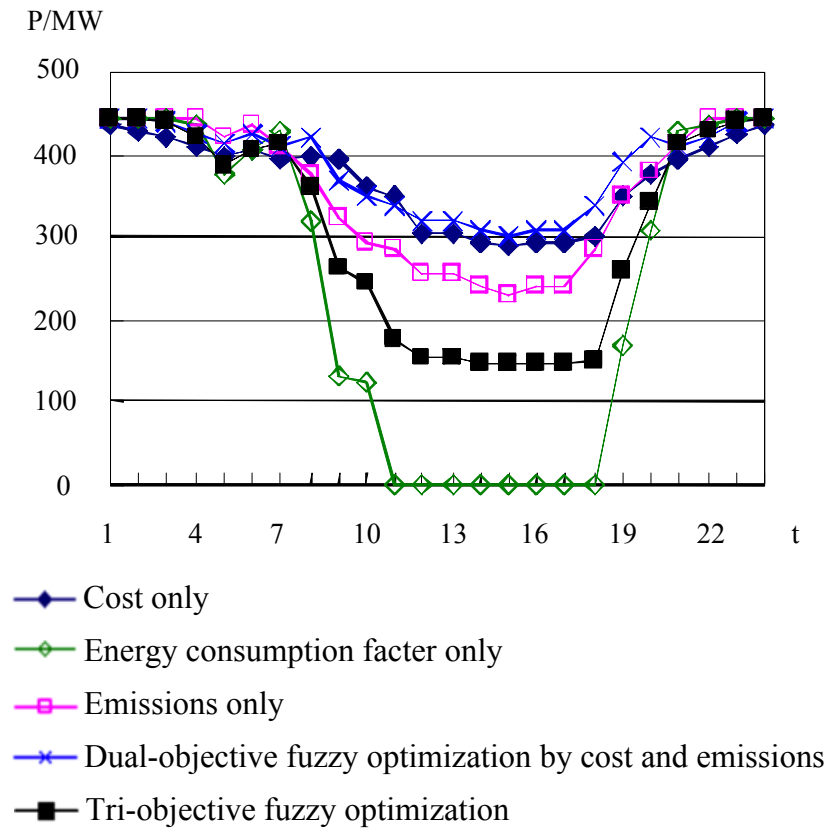

Fig. (5). Generator 4 output power curves. 


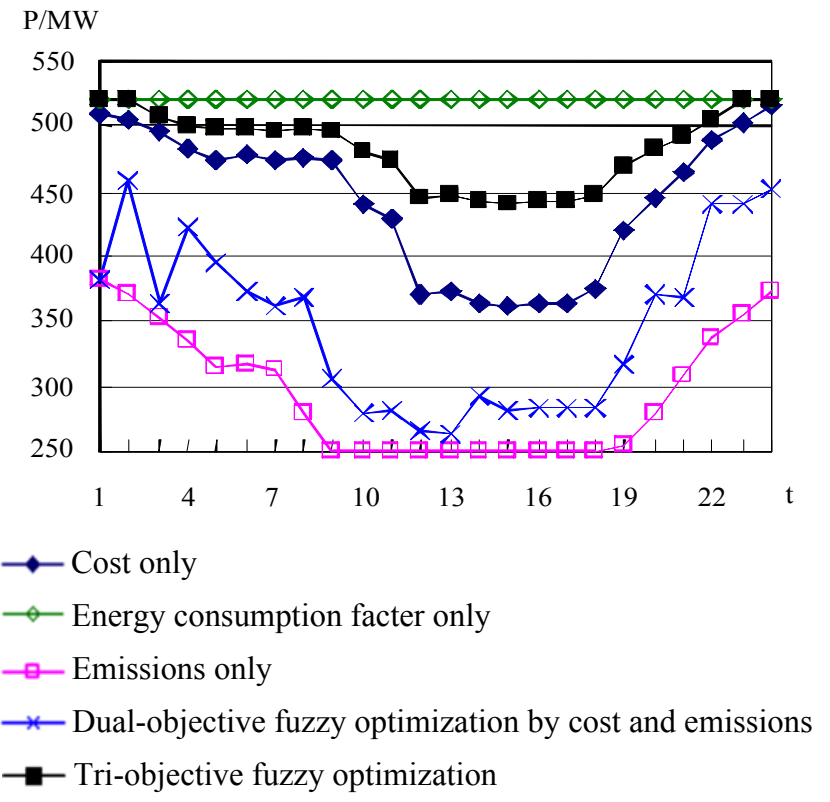

Fig. (6). Generator 5 output power curves.

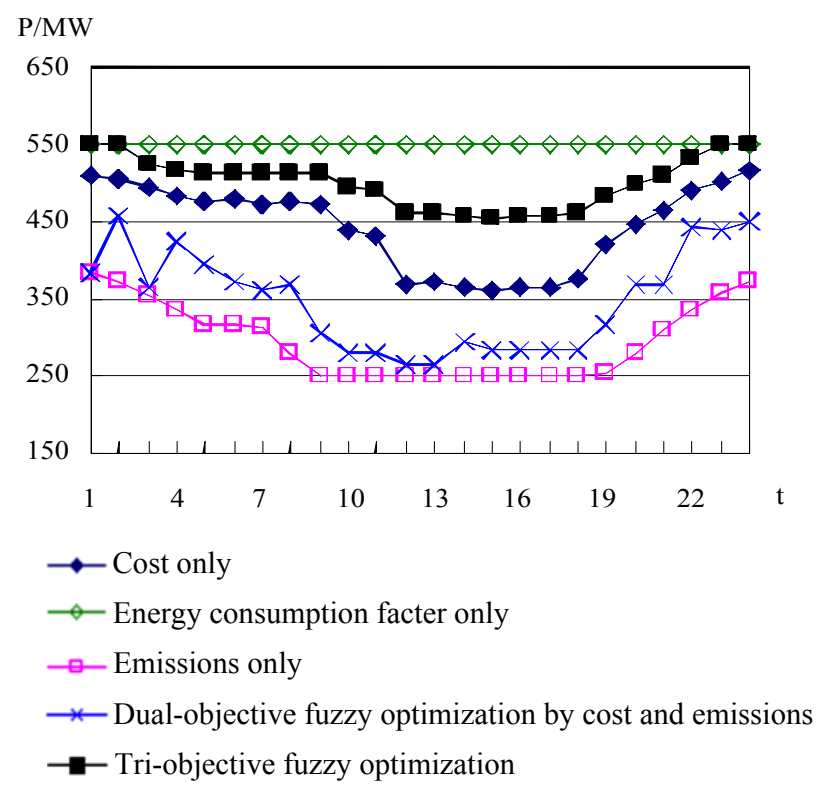

Fig. (7). Generator 6 output power curves.

Compared with the target values by the single-objective optimizations and the dual-objective optimizations, the triobjective fuzzy optimization's result is obviously better. Its cost for power purchase increased by $1.93 \%$, and the $N O_{x}$ emissions only increased by $2.82 \%$, but the energy consumption factor, by $11.52 \%$ lower, which fully reflects the balance between energy saving, environmental protection, and economic. As can be seen from Figs. (2-7), the power output of generators with lower energy consumption increases significantly, while the higher decreases at the same time. The comparison of results between the new model with the single objective optimization model and the traditional model of economic dispatch has proved that the dispatch model is improved.

\section{CONCLUSION}

Energy and environmental problems are the primary issues to restrict the development in many countries. It is also a challenge faced by the electric power industry. The unique character of the electric power system generation dispatch mechanism based on resource value is to measure the natural resource value according to the current level of social and economic development. The implementation of value based dispatch abides by the market mechanism and competitive mechanism to realize the optimization allocation. As a new generation of dispatch theory, the value based dispatch is the inheritance and development of traditional form, which can meet the future demand of the electric power industry and accomplish the mission of optimizing resource utilization structure and promoting the sustainable development of economy and society.

\section{CONFLICT OF INTEREST}

The authors confirm that this article content has no conflict of interest.

\section{ACKNOWLEDGEMENTS}

This study is supported by National Natural Science Foundation of China (No.51077087 and No. 51007047) and Social Science Fund of Jilin Province (No.2013BS76).

\section{REFERENCES}

[1] Allen J.W.; Bruce F.W. Power generation, operation and control, New York: John Wiley \& Sons Inc., 1996.

[2] Farag, A.; Al-baiyat, S.; Cheng, T.C.; Economic load dispatch multiobjective optimization procedures using linear-programming techniques. IEEE Trans. Power Syst. 1995, 10, 731-738.

[3] Yu, E.; Liu, G.; Energy Management Systems, Beijing: Science Press, 1998.

[4] W. Li, Economic operation of power system - model and method, Chongqing: Chongqing University Press, 1989.

[5] Dhillon, J.S.; Parti S.C; Kothari, D.P. Stochastic economic emission load dispatch. Elec. Power Syst. Res., 1993, 26, 179-186.

[6] Talaq, J.H.; Ei-hawary, F.; E-hawary, M.E. A summary of environmental/economic dispatch algorithms. IEEE Trans. Power Syst., 1994, 9, 1508-1516,

[7] Shahidehpou, S.M ; Hatim, Y.; Zuyi, L. Market operations in electric power system-forecasting, scheduling, and risk management. New York: John Wiley \& Sons, 2002.

[8] Kirschen, D.S.; Strbac, G. Fundamentals of power system economics, London: John Willey \& Sons, 2004.

[9] Han, X. Consideration of power system operation dispatch study under electricity market. Proc. CSU-EPSA., 2008, 20, 17-21.

[10] Su, C.; Daniel, K. Direct participation of demand-side in a poolbased electricity market. Power. Syst. Tech., 2007, 31, 7-15.

[11] Zhang, Q.; Wang, X.; Wang, J.; Feng, C.; Liu, L. Survey of demand response research in deregulated electricity markets. Auto Elec. Power Syst., 2008, 32, 97-106.

[12] Miranda, V.; Hang, P.S.; Economic dispatch model with fuzzy wind constraints and attitudes of dispatchers. IEEE Trans. Power Syst., 2005, 20, 1322-1331.

[13] Liang, R.; Liao, J. A fuzzy optimization approach for generation scheduling with wind and solar energy systems. IEEE Trans. Power Syst., 2007, 22, 1165-1173.

[14] Hetzer, J.; Yu, D.C. An economic dispatch model incorporating wind power. IEEE Trans. Energ. Convers., 2008, 23, 603-611.

[15] Ummels, B.; Gibescu, C.M.; Pelgrum, E.; Kling, W. L.; Brand, J.A. Impacts of wind power on thermal generation unit commitment and dispatch. IEEE Trans. Energ. Convers., 2007, 22, 44-51.

[16] Lee, T.Y. Optimal spinning reserve for a wind-thermal power system using EIPSO. IEEE. Trans. Power. Syst., 2007, 22,16121621.

[17] Development and reform commission of china, "Energy-saving power generation dispatch method", 2007. [online] Available; 
http://www.nea.gov.cn/2007-08/28/c_131053158.htm [accessed on 2 August 2014].

[18] Yan, Y.; Ma, K.; Yu, Z.; Zhu, W.; Chen, G. Primary research on improvement in generation dispatching mode to implement energy conservation and environmental protection and economic dispatching. Elect. Power, 2007, 40, 6-9.

[19] Zhao, W.; Lin, C.; Sun, B. Study on Economic dispatch method of the optimal composite coal loss under security constraints. Power. Syst. Protect. Cont., 2010, 38, 18-22.

[20] Xu, C.; Yang, L.; Liu, F. Discuss on the union implementation scheme of energy conservation measures and electricity marketability methods. Auto Elect. Power Syst., 2007, 31, 99-103.

[21] Han, X.; Yang, M.; Zhang, L. Contemplation of smart grid development promoted by value based dispatch. Auto Elect. Power Syst., 2010, 34, 5-9.
[22] Luo, L. Circular Economics: Coupling of material circle and value circle. Tianjin. Social. Sci., 2005, 2, 73-77.

[23] Hu, G.; He, R. Multi-objective short-term optimization dispatching for hydrothermal power systems using interactive fuzzy satisfying method. J. North China Elect. Power Univ., 2007, 34, 1-5.

[24] Ma, R. A novel bi-objective fuzzy optimal model of short-term trade planning considering environmental protection and economic profit in deregulated power system. Proc. CSEE., 2002, 22, 104108.

[25] Zhang, X. An improved method of interactive multi-objective decision-making based on objective Satisfaction Degree. Syst. Eng., 2004, 22, 10-13.

[26] Han, X.; Liu, Z. Optimal unit commitment considering units ramprate limits. Power Syst. Tech., 1994, 18,11-16

(C) Wang and Han; Licensee Bentham Open

This is an open access article licensed under the terms of the Creative Commons Attribution Non-Commercial License (http://creativecommons.org/licenses/by-nc/4.0/) which permits unrestricted, non-commercial use, distribution and reproduction in any medium, provided the work is properly cited. 